\title{
Properties of ZnO:Al Films Prepared by Spin Coating of Aged Precursor Solution
}

\author{
Shankar Prasad Shrestha, ${ }^{*}$ Rishi Ghimire, ${ }^{\dagger}$ Jeevan Jyoti Nakarmi, ${ }^{\dagger}$ Young-Sung Kim, ${ }^{\ddagger}$ \\ Sabita Shrestha, ${ }^{\S}$ Chong-Yun Park, ${ }^{\S}$ and Jin-Hyo Boo ${ }^{\#, *}$ \\ Department of Physics, Patan Multiple Campus, Tribhuvan University, Kathmandu, Nepal. *E-mail: shankarpds@yahoo.com \\ ${ }^{\dagger}$ Department of Physics, Kritipur Campus, Tribhuvan University, Kathmandu, Nepal \\ ${ }^{*}$ Technology Innovation Center, Sungkyunkwan University, Suwon 440-746, Korea \\ ${ }^{\S}$ Department of Physics and Center for Nanotubes and Nanostructured Composite, \\ Sungkyunkwan University, Suwon 440-746, Korea \\ ${ }^{\#}$ Department of Chemistry and Institute of Basic Science, Sungkyunkwan University, Suwon 440-746, Korea. \\ *E-mail: jhboo@skku.edu \\ Received November 4, 2009, Accepted November 27, 2009
}

\begin{abstract}
Transparent conducting undoped and $\mathrm{Al}$ impurity doped $\mathrm{ZnO}$ films were deposited on glass substrate by spin coat technique using 24 days aged $\mathrm{ZnO}$ precursor solution with solution of ethanol and diethanolamine. The films were characterized by UV-Visible spectroscopy, X-ray diffraction (XRD), scanning electron microscope (SEM), electrical resistivity $(\rho)$, carrier concentration $(n)$, and hall mobility $(\mu)$ measurements. XRD data show that the deposited film shows polycrystalline nature with hexagonal wurtzite structure with preferential orientation along (002) crystal plane. The SEM images show that surface morphology, porosity and grain sizes are affected by doping concentration. The $\mathrm{Al}$ doped samples show high transmittance and better resistivity. With increasing Al concentration only mild change in optical band gap is observed. Optical properties are not affected by aging of parent solution. A lowest resistivity $(8.5 \times$ $10^{-2} \mathrm{ohm} \mathrm{cm}$ ) is observed at 2 atomic percent (at.\%) Al. With further increase in $\mathrm{Al}$ concentration, the resistivity started to increase significantly. The decrease resistivity with increasing $\mathrm{Al}$ concentration can be attributed to increase in both carrier concentration and hall mobility.
\end{abstract}

Key Words: Sol-Gel, Al-doped zinc oxide, Electrical properties, Optical properties

\section{Introduction}

In the recent years, $\mathrm{ZnO}$ have received considerable attention due to its applications in electrical, optical, mechanical and scientific research as well as industry. $\mathrm{ZnO}$ is a wide band gap ntype semiconductor with hexagonal wurtzite structure. It is a versatile material having potential use in many applications like solar cell, transparent conducting electrode, ultraviolet and blue light emitting diodes, laser diodes, thin film transistor, surface acoustic wave (SAW) devices and gas sensors. ${ }^{1-6}$ For transparent conducting application the film should have low resistivity, high transmittance in the visible range and good stability against corrosive environment. Indium tin oxide (ITO) film have good electrical and optical properties and they been used widely in transparent conductor application. Al doped $\mathrm{ZnO}$ (AZO) have good electrical and optical properties for transparent conductor application and can be an alternate to ITO. ${ }^{7,8}$ The material $\mathrm{Al}$ is a cheap, abundant and non-toxic. Therefore, it can be an ideal candidate to replace indium. Further AZO films have good stability over hydrogen plasma. ${ }^{9}$

Thin films of $\mathrm{ZnO}$ have been deposited by using several deposition techniques, such as magnetron sputtering, ${ }^{10,11}$ pulsed laser deposition, ${ }^{12}$ chemical vapor deposition, ${ }^{13}$ spray pyrolysis, ${ }^{14,15}$ and sol-gel method. ${ }^{16-20}$ The sol-gel process is one of the attractive techniques for film deposition because of low equipment cost, non vacuum requirement, low temperature processing, easy to dope and also offers the possibility of preparing large area coating. Also, the thin films by sol gel technique have good homogeneity, excellent compositional control with good electrical and optical properties. It is well known that the film properties deposed by the sol-gel technique are determined by preparation parameters. ${ }^{21}$ The study on the effect of the aging time of the starting solution on the properties of $\mathrm{ZnO}: \mathrm{F}$ thin films show that resistivity of the $\mathrm{ZnO}: \mathrm{F}$ thin films decreases with increasing aging of the precursor solution. In this work we present the study on the effects of $\mathrm{Al}$ doping on the electrical and optical properties $\mathrm{ZnO}$ thin films prepared by sol-gel spin coating of highly aged precursor solution.

\section{Experimental Procedure}

The undoped and $\mathrm{Al}$ doped $\mathrm{ZnO}$ films were prepared by solgel spin coating of colloidal suspensions containing different $\mathrm{Al}$ concentrations on glass substrates. The $\mathrm{ZnO}$ precursor solution was prepared by dissolving zinc acetate $\left(\mathrm{CH}_{3} \mathrm{COOH}\right.$. $2 \mathrm{H}_{2} \mathrm{O}$, pure- Merck A. R. grade) in solution of ethanol and diethanolamine (DEA) at room temperature. DEA was used as a stabilizer. The molar ratio of DEA to zinc acetate was maintained at 1.0 and the concentration of zinc acetate was $0.1 \mathrm{M}$. The solution was stirred to about two hour at $60{ }^{\circ} \mathrm{C}$ till a clear and homogeneous solution is obtained. The precursor solution was filtered through WHATMAN filter paper and was finally aged for 24 days at room temperature. Al doping is achieved by adding hexahydrate aluminum chloride $\left(\mathrm{AlCl}_{3} \cdot 6 \mathrm{H}_{2} \mathrm{O}\right)$ solution 
in the parent solution. The $\mathrm{Al} / \mathrm{Zn}$ ratio in the solution was varied from 1 at. $\%$ to 5 at. $\%$. The films were prepared in microscope glass slide. At first glass slide were cleaned with detergent and ultrasonic treatment. Then, it was washed with deionized water and acetone. Spin coating was performed at room temperature, with a rate of $3400 \mathrm{rpm}$ for $30 \mathrm{~s}$. The deposited film is preheated at $130{ }^{\circ} \mathrm{C}$ for $5 \mathrm{~min}$ and then at $450{ }^{\circ} \mathrm{C}$ for $10 \mathrm{~min}$. After that the same coating process is repeated for 9 times to get uniform thick film. The crystallinity of the $\mathrm{ZnO}$ films was determined by $\mathrm{X}$ ray diffractometer.

X-ray diffraction patterns were obtained with a RIGAKU RINT 2200 Series X-ray automatic diffractometer using the $\mathrm{Cu}$ Ka radiations $(\lambda=1.54059 \AA \mathbf{A})$. Surface morphologies and cross section image of the film were obtained by using field emission scanning electron microscope (FE-SEM, JEOL 6330). The thickness of the film was determined from SEM micrograph. The optical properties of undoped and Al-doped $\mathrm{ZnO}$ were determined from transmission measurement at room temperature. Optical transmittance was obtained using USB 2000 photonics spectrometer. The electrical properties were determined from resistivity and hall coefficient measurement at room temperature. The electrical resistivity, carrier concentration and mobility measurement of the films was done using Hall Effect measurement system (Ecopia, HMS-3000).

\section{Results and Discussion}

Fig. 1 depicts the X-ray diffraction patterns of nine layer coated $\mathrm{ZnO}$ thin films. The XRD profile show three pronounced diffraction peaks at $2 \theta=31.72,34.45$ and 36.21 position. These peaks corresponds to the $\left(\begin{array}{lll}1 & 0 & 0\end{array}\right),\left(\begin{array}{lll}0 & 0 & 2\end{array}\right)$, and (llll $\left.\begin{array}{lll}1 & 1\end{array}\right)$ planes of $\mathrm{ZnO}$. This indicates that $\mathrm{ZnO}$ films prepared by sol-gel spin coating technique are polycrystalline with hexagonal structure. From the diffraction profile we see that the (002) peak is much stronger than the other peaks. This implies that the $\mathrm{ZnO}$ films are strongly $c$-axis oriented.

Fig. 2 (a), (b), (c) and (d) depict the SEM micrographs of the surface of $\mathrm{Al}$ doped $\mathrm{ZnO}$ thin films with different $\mathrm{Al}$ concentration $(0,1,2$ and 4 at.\%) for constant substrate temperature. The surface morphology of the deposited films is observed to be smooth and plane without crack. From the figure we find that the microstructure of the films consisted of many round shaped crystalline particles. The microstructure formed is found to be uniform and compact interconnected grains. The average grain size of the undoped $\mathrm{ZnO}$ thin films is around $42 \mathrm{~nm}$. Both undoped and $\mathrm{Al}$ doped $\mathrm{ZnO}$ film show porous microstructure however at high doping level porosity is reduced. These SEM micrographs show that the surface morphology of the films depends on the concentration of the dopant. The grain size of the deposited films decreases with increase of the concentration of Al. This behaviour could be related to the difference between the ionic radius of $\mathrm{Zn}$ and the doping elements $\mathrm{Al} .{ }^{14}$ Further, with increasing $\mathrm{Al}$ concentration, the microstructure of the film became denser. Fig. 2 (e) and (f) depicts the cross-sectional SEM images of undoped and 2 at. $\% \mathrm{Al}$ doped $\mathrm{ZnO}$ thin films. The thickness of the undoped film and the Al doped films determined from the SEM image is found to be nearly equal and it is around $145 \mathrm{~nm}$.

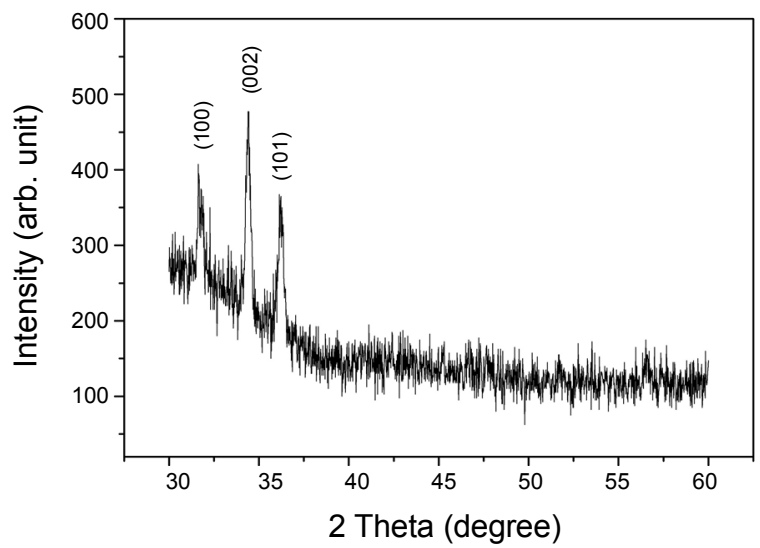

Figure 1. XRD pattern for $\mathrm{ZnO}: \mathrm{Al}$ film prepared from 24 days aged $\mathrm{ZnO}$ precursor solution.

(a) 0 at. $\%$

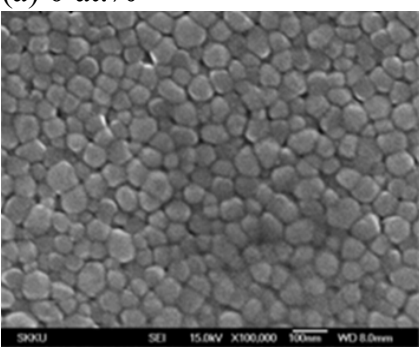

(c) 2 at. $\%$

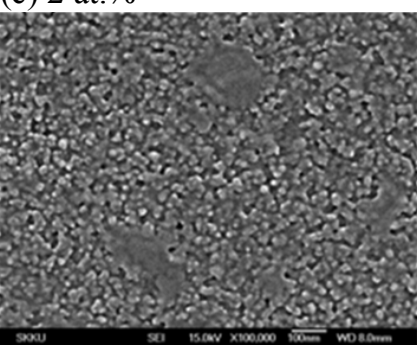

(e) 0 at. $\%$

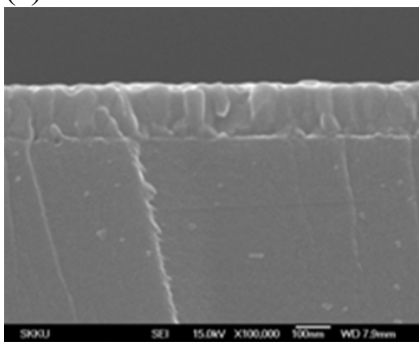

Figure 2. SEM images of $\mathrm{ZnO}: \mathrm{Al}$ films with different $\mathrm{Al}$ concentration (a) 0 at. $\%$, (b) 1 at. \%, (c) 2 at. $\%$, and (d) 4 at. $\%$. Cross-sectional SEM images of $\mathrm{ZnO}: \mathrm{Al}$ films with at $\mathrm{Al}$ concentration of (e) 0 at.\% and (f) 2 at. $\%$.

Fig. 3 depicts the variation of optical transmittance and absorbance of undoped and $\mathrm{Al}$ doped $\mathrm{ZnO}$ films on microscope glass substrate. Both undoped and Al doped films exhibit high transparent in the UV-Visible range. The transmittance of Al doped films is in between 85 to $91 \%$ in the visible range, which is found to be better than undoped $\mathrm{ZnO}$ film. This is may be due to more porous nature of the $\mathrm{Al}$ doped film. In the spectra, a sharp ab- 


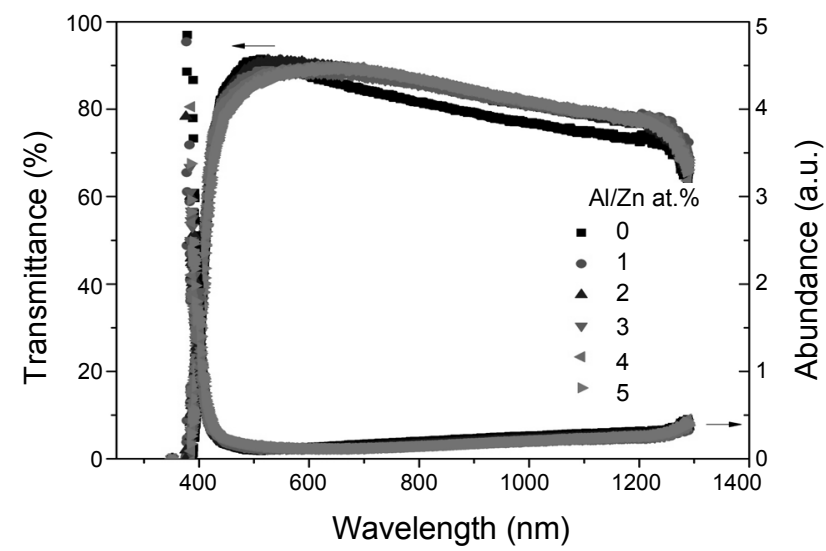

Figure 3. Optical transmittance of $\mathrm{Al}: \mathrm{ZnO}$ films prepared from 24 days aged precursor solution.

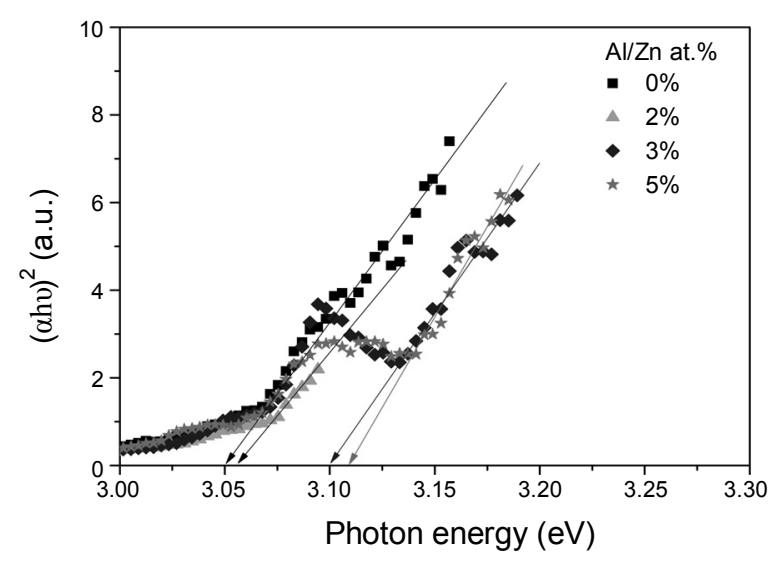

Figure 4. Plot of $(\alpha h v)^{2} v s \mathrm{~h} v$ for $\mathrm{Al}: \mathrm{ZnO}$ films with $\mathrm{Al}$ concentration.

sorption transition with absorption edge at around $400 \mathrm{~nm}$ occurs in the visible region. The absorption edge corresponds to the intrinsic band gap of $\mathrm{ZnO}$. Comparing the transmittance and absorption spectra of 4 days aged sample (not shown here) with the transmittance and absorbance spectra of 24 days aged samples (Fig. 3), we find that, the transmittance of the film does not show appreciable change with the aging of the parent solution. Also, there is no remarkable change on band edge transition with the aging of the parent solution.

The detail information about the band gaps, were obtained by analyzing the dependence of absorption coefficient on photon energy in the high absorption regions. The optical band gap of the films was determined from the absorption spectra by the following relationship. ${ }^{22}$

$$
(\alpha h v)=A\left(h v-E_{g}\right)^{m}
$$

Where $\mathrm{A}$ is an energy-independent constant between $10^{7}$ and $10^{8} \mathrm{~m}^{-1} ; \mathrm{h}$ is the Planck constant; $\mathrm{n}$ is the frequency of the incident photon; $\mathrm{E}_{\mathrm{g}}$ is the optical band gap and $\mathrm{m}$ is a constant that determines the type of optical transition. Its values are taken as 2 for indirect and $1 / 2$ for direct allowed transitions. Fig. 4 depicts the plot of $(\alpha h v)^{2}$ versus photo energy (hv) plot for the films deposited at different doping concentration ( $0 \%$ to $5 \%)$.

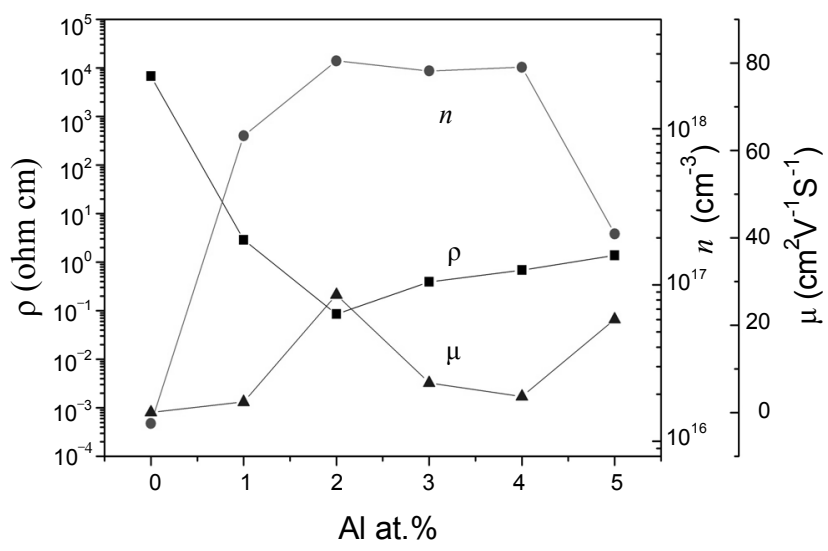

Figure 5. Variation of resistivity, carrier concentration and mobility with $\mathrm{Al}$ concentration.

The optical band gaps of the deposited films were determined by extrapolating the linear portion of $(\alpha h v)^{2}$ versus hv to abscissa. With increasing Al concentration the band gap value increases from $3.05 \mathrm{eV}$ to $3.11 \mathrm{eV}$. The widening of optical band gap with aluminum doping is well described by Burstein-Moss effect. ${ }^{23,24}$ By doping with $\mathrm{Al}$, the aluminum atoms occupy the zinc sites in the $\mathrm{ZnO}$ lattice. Thus, at room temperature they act as singly ionized donors giving one extra electron. These donor electrons occupy the states at the bottom of the conduction band. Therefore, as doping concentration is increased, these states get filled with donor electrons, which results in widening of a band gap. This is well known as Burstein-Moss effect.

The electrical resistivity $\rho$ was measured at room temperature by four-probe method. The Hall coefficient was measured at a magnetic field of $0.5 \mathrm{~T}$. The thickness of the film was determined from SEM images. Fig. 5 depicts the variation of resistivity $(\rho)$, carrier concentration $(n)$ and mobility $(\mu)$ of Al doped $\mathrm{ZnO}$ films with doping concentration. The resistivity first decrease with increasing Al concentration and a lowest resistivity $\left(8.5 \times 10^{-2}\right.$ $\mathrm{ohm} \mathrm{cm}$ ) is obtained at a doping concentration is 2 at.\%. With further increase in $\mathrm{Al}$ concentration the resistivity value started to increase significantly. The decrease resistivity with increase in $\mathrm{Al}$ concentration can be attributed due to increase in carrier concentration and also due to increase in mobility, which is seen in the figure. Beyond doping concentration of 2 at. \% the mobility decreases drastically but only small change in carrier concentration is observed. Therefore, the increase in resistivity can be attributed due to change in carrier mobility.

When a small amount of $\mathrm{Al}$ is introduced in the $\mathrm{ZnO}$ matrix, the $\mathrm{Al}$ atoms occupy the sites of $\mathrm{Zn}$ atoms. Since $\mathrm{Al}$ atom has one more valence electron in outermost orbit than $\mathrm{Zn}$, the replacement of $\mathrm{Zn}$ atom by $\mathrm{Al}$ atom produces one free electron. Thus, replacement of $\mathrm{Zn}^{+2}$ ion with $\mathrm{Al}^{+3}$ leads to $n$ type doping, which leads to the increase in carrier concentration and cause decreases in the resistivity. When the doping concentration is increased above 2 at. $\%$ the resistivity of the film increases. It is because beyond certain doping concentration (beyond solid solution limit), the doping atoms does not occupy the lattice sites but instead may result in some kind of neutral defects. These neutral $\mathrm{Al}$ atoms do not contribute free carrier. Thus, at high doping level the neutralized $\mathrm{Al}$ atoms produce a disorder in the lattice. 
These act as a scattering center, which in turn increases the resistivity. Our result is in consistent with the results of Mass et. $a .^{25}$ In their report, the $\mathrm{ZnO}$ :Al film were prepared by pulsed laser deposition technique and the increase of resistivity with doping concentration above 2 at. $\%$ were attributed due to the sharp decrease of mobility.

Comparing, the electrical properties for $\mathrm{ZnO}$ film prepared from 24 days (Fig. 5) and 4 days aged solution (not shown here), we find that the resistivity of the film prepared from 24 days aged solution is lower the film prepared from 4 days aged solution. However, the trend of the curve in both 24 days aged sample and 4 days aged sample is similar and lowest resistivity is always observed at 2 at.\% of doping level. In the case of carrier concentration also highest carrier concentration in both cases is observed at same doping level that is at 2 at.\% and trend of increase and decrease in carrier concentration with doping level is also somewhat similar. In case for mobility the lowest mobility in both case does not occur at the same doping level and also the trend for curve for different doping level also is different.

\section{Conclusions}

Aluminum doped $\mathrm{ZnO}$ as a transparent conducting oxide is deposited in glass substrate using sol gel spin coat technique. The ZnO:Al crystals show preferential orientation along (002) crystal plane. The SEM analysis shows that, the porosity of the films seems to increase with increasing the number of coatings. The Al impurity doping is observed to influence the surface morphology of the film. The grain size of the film is observed to decrease with increase of the concentration of Al. The transmittance of $\mathrm{ZnO}$ :Al film of the samples aged at two different ageing times, we find that, the transmittance of the film does not show appreciable change with the aging of the parent solution. Only slight changes in band gap is observed with increasing $\mathrm{Al}$ concentration. The minimum resistivity always occurs at the same doping level (2 at.\%) irrespective of the aging of the parent solution. The lowest resistivity value of value for the samples from 4 days and 24 days aged solution is found to be $1.56 \times 10^{-1}$ $\mathrm{ohm} \mathrm{cm}$ and $8.5 \times 10^{-2} \mathrm{ohm} \mathrm{cm}$, respectively. The decrease resistivity with increase in $\mathrm{Al}$ concentration can be attributed to increase in carrier concentration as well as hall mobility.
Acknowledgments. This work was supported by the National Research Foundation of Korea (Grants Nos. KRF-2008-005J00702 and R01-2006-000-10396-0).

\section{References}

1. Chen, Y. F.; Ko, H. J.; Hong, S. K.; Sekiuchi, T.; Yao, T.; Segawa, Y. J. Vac. Sci. Technol. B 2000, 18, 1514.

2. Jeong, S. H.; Lee, J. W.; Lee, S. B.; Boo, J. H. Surf. Coat. Technol. 2003, 174, 187.

3. Lee, H. W.; Choi, B. G.; Shim, K. B.; Oh, Y. J. J. Ceram. Proc. Res. 2005, 6, 880 .

4. Smith, A. Thin Solid Films 2000, 376, 47.

5. Li, H.; Wang, J.; Liu, H.; Zhang, H.; Li, X. J. of Cryst. Growth 2005, 275, e943.

6. Chang, J. F.; Kuo, H. H.; Leu, I. C.; Hon, M. H. Sens. \& Actua. B 2002, $84,258$.

7. Guille'n, C.; Herrero, J. Thin Solid Films 2006, 515, 640.

8. Lin, K.; Tsai, P. Mater. Sci. and Engin. B 2007, 139, 81.

9. Weller, H. C.; Mauch, R. H.; Bauer, G. H. Sol. Energ. Mat. Sol. C 1992, 27, 217.

10. Szyszka, B.; Jäger, S. J. Non-Cryst. Solids 1997, 218, 74.

11. Ellmer, K.; Wendt, R. Surf. Coat. Technol. 1997, 93, 21.

12. Lee, S. Y.; Li, Y.; Lee, J. S.; Lee, J. K.; Natasi, M.; Crooker, S. A.; Jia, Q. X. Appl. Phys. Lett. 2004, 85, 218.

13. Barnes, T. M.; Leaf, J.; Fry, C.; Wolden, C. A. J. Cryst. Growth 2005, 274, 412.

14. Nunes, P.; Fortunato, E.; Tonello, P.; Fernandes, F. B.; Vilarino, P.; Martins, R. Vacuum 2002, 64, 281.

15. Shrestha, S. P.; Basnet, P. Proc. of SPIE 2008, 6793, 67930I.

16. Natsume, Y.; Sakata, H. Thin Solid Films 2000, 372, 30.

17. Xu, Z. Q.; Deng, H.; Li, Y.; Guo, Q. H.; Li, Y. R. Materials Research Bulletin 2006, 41, 354.

18. Li, H.; Wang, J.; Liu, H.; Zhang, H.; Li, X. J. of Cryst. Growth 2005, $275,943$.

19. Xue, S. W.; Zu, X. T.; Xiang, X.; Deng, H.; Xu, Z. Q. Eur. Phys. J. Appl. Phys. 2006, 35, 195.

20. Lee, J. H., Ko, K. H.; Park, B. O. J. of Crystal Growth 2003, 247, 119.

21. Lin, K.; Tsai, P. Sci. Eng. B 2007, 139, 81.

22. Pankove, J. I. In Optical Processes in Semiconductors; Englewoord Cliffs, N., Ed.; Prentice-Hall Inc.: 1971.

23. Bursteib, E. Phys. Rev. 1954, 93, 632.

24. Moss, T. S. Proc. Phys. Soc. Lond. B 1954, 67, 775.

25. Mass, J.; Bhattacharya, P.; Katiyar, R. S. Mater. Sci. Eng. B 2003, 103,9 . 